\title{
Auditory backup alarms: distance-at-first- detection via in-situ experimentation on alarm design and hearing protection effects
}

\author{
Khaled Alali ${ }^{\text {a, }}$, and John G. Casali ${ }^{\text {b }}$ \\ andustrial and Management Systems Engineering, Kuwait University, P.O.Box-5969, 13060, Safat, Kuwait, \\ Phone: 965-24983632 \\ ${ }^{b}$ Grado Department of Industrial and Systems Engineering, Virginia Tech, Blacksburg, VA 24061, USA, Phone: \\ 540-231-5073
}

\begin{abstract}
The purpose of this study was to assess normal hearing listeners' performance in detecting a stationary backup alarm signal and to quantify the linear distance at detection point. Method: Detection distances for 12 participants with normal hearing were measured while they were fitted with 7 hearing protectors and while they were unoccluded (open ear). A standard (narrowband) backup alarm signal and a broadband (pulsed white noise) backup alarm signal from Brigade ${ }^{[1]}$ were used. The method of limits, with distance as the physical measurement variable and threshold detection as the task, was employed to find at which distance the participant could first detect the backup alarms. Results: A within-subject Analysis of Variance (ANOVA) revealed a significant main effect of the listening conditions on the detection distance in feet. Post hoc analyses indicated that the Bilsom L3HV conventional passive earmuff (at $1132.2 \mathrm{ft}$ detection distance) was significantly poorer compared to all other HPDs and the open ear in detection distance achieved, and that there were no statistically-significant differences between the unoccluded ear $(1652.3 \mathrm{ft})$, EB-15-Lo BlastPLG ${ }^{\mathrm{TM}}(1546.2 \mathrm{ft})$, EB-15-Hi BlastPLG ${ }^{\mathrm{TM}}(1543.4 \mathrm{ft})$, E-A-R/3M Combat Arms $^{\mathrm{TM}}$ earplug-nonlinear, level-dependent state $(1507.8 \mathrm{ft}), \mathrm{E}-\mathrm{A}-\mathrm{R} / 3 \mathrm{M} \mathrm{HiFi}{ }^{\mathrm{TM}}$ earplug $(1497.7 \mathrm{ft})$, and Bilsom Impact ${ }^{\mathrm{TM}}$ dichotic electronic earmuff $(1567.2 \mathrm{ft})$. In addition, the E-A-R/3M Combat Arms ${ }^{\mathrm{TM}}$ earplug-passive steady state resulted in significantly longer detection distances than only the open ear condition, at $1474.1 \mathrm{ft}$ versus $1652.3 \mathrm{ft}$ for the open ear. ANOVA also revealed a significant main effect of the backup alarm type on detection distance. The means were $1600.9 \mathrm{ft}$ for the standard (narrowband) backup alarm signal, and a significantly closer $1379.4 \mathrm{ft}$ was required for the Brigade broadband backup alarm signal. Discussion: For on-ground workers, it is crucial to detect backup alarm signals as far away as possible rather than at close distances since this will provide them more time to react to approaching vehicles. The results of this study suggest that as the attenuation of the hearing protectors increases, precautions should be considered by safety professionals. This is because, as it was the case with the Bilsom passive earmuff and E-A-R/3M Combat Arms ${ }^{\mathrm{TM}}$ earplug-passive steady state, high attenuation minimizes the detection distance and as a result on-foot workers will have less time to react to any approaching vehicle. The main effects of the type of backup alarm signal demonstrated a statistically-significant advantage of the standard backup alarm over the broadband backup alarm on detection distance in feet. The magnitude of the improvement produced by the standard backup alarm was 221.5 feet, a very large margin. For example, with a vehicle backing at $10 \mathrm{mph}$, the $221.5 \mathrm{ft}$ decrease in detection distance with the Brigade alarm equates to the vehicle arriving 15 seconds sooner at the worker from the point at which its alarm was first heard.
\end{abstract}

Keywords: Hearing protector, hearing protection device, backup alarm, reverse alarm, detection distance, broadband backup alarm, auditory detection

\footnotetext{
*Corresponding authors. Emails: khaled.alali@ku.edu.kw, jcasali@vt.edu
} 


\section{Introduction}

Due to their design, many construction vehicles and mobile equipment (e.g., backhoes, loaders, excavators, dump trucks, etc) have an obstructed rear view which makes it difficult for drivers to view the area behind their vehicles to insure it is free of onfoot workers. For this reason, backup (i.e., reverse) alarms are used to warn on-foot workers of the danger imposed by vehicles when they are reversing. The use of these alarms is common in general industry as well as in construction and has been since the 1970's. In 2008, Casali \& Lancaster $^{[2]}$ interviewed many subject matter experts, including construction site supervisors, construction workers and vehicle operators, and construction engineers. The interviews' outputs indicated that the backup alarm is the prevalent and most ubiquitous auditory warning in construction sites.

The Occupational Safety \& Health Administration (OSHA) has two regulations that have bearing on the use of backup alarms on construction motor vehicles and moving machines. For motor vehicles, OSHA regulations ${ }^{[4]}$ state, "No employer shall use any motor vehicle equipment having an obstructed view to the rear unless: (b)(4)(i) The vehicle has a reverse signal alarm audible above the surrounding noise level or: (b)(4)(ii) The vehicle is backed up only when an observer signals that it is safe to do so" (Part 1926.601[b][4]). Also, for moving machines, OSHA regulations ${ }^{[3]}$ state, "No employer shall permit earthmoving or compacting equipment which has an obstructed view to the rear to be used in reverse gear unless the equipment has in operation a reverse signal alarm distinguishable from the surrounding noise level or an employee signals that it is safe to do so" (Part 1926.602[a][9]). Despite OSHA's backup alarms regulations, fatalities from backing accidents occur with alarming frequency. In 2001, Pratt et al. ${ }^{[5]}$ reported that during a six-year period beginning in 1992,154 on-foot workers were fatally injured due to being struck by construction vehicles in highway/street work zones. Among those incidents, around $51 \%$ were caused by backing construction vehicles. In their report, Pratt et al. presented some of the cases involved backing accidents in construction sites. In many of these cases, the backup alarm was reported to be sounding during the time of the accident. Similar results were revealed by Purswell \& Purswell $^{[6]}$ in 2001, when they investigated OSHA accident reports, looking for backing accidents. They found that approximately $43 \%$ of the investigated backing accidents occurred while the backup alarm was operable. Apparently, these statistics make the effectiveness of commercial backup alarms questionable, in terms of whether the backup alarms were inaudible, not localizable, or simply not heeded.

Although, while depending upon their noise exposures construction workers are either encouraged or required by OSHA to wear hearing protection devices (HPDs) to avoid hearing loss, improper selection of the HPD type/design may impair the workers' ability to detect important signals, creating a hazardous situation. In other words, while solving the important problem of noise exposure, another problem of reducing auditory situation awareness may be created. Detecting backup alarm signals at adequate distances is crucial for workers' safety to afford ample time to react to any backing vehicles. With these issues in mind, the experiment reported herein was conducted to investigate how normalhearing listeners detect backup alarm signals in the linear distance dimension (detection distance in $\mathrm{ft}$ ) under different types of HPDs as compared to the open ear. The devices used included the most recent technologies in augmented passive and active HPDs available in the market circa mid-2010, in addition to the conventional passive HPDs that are marketed for the construction industry. All HPDs were compared against the unoccluded ear. In addition, the effect of a standard (narrowband) backup alarm signal and a commercially-available broadband (pulsed white noise) backup alarm signal on the detection distance was investigated.

\section{Methodology}

\subsection{Experimental design}

To assess the participants' performance in detecting a stationary backup alarm signal and quantifying the linear distance at detection point, an $8 \times 2$ completely within-subjects experiment was adopted with two independent variables (Figure 1). The independent variables were: the hearing protection (or open ear) condition ( 8 levels) and the type of backup alarm signal (2 levels). A discussion of each of the independent variables is provided below. 


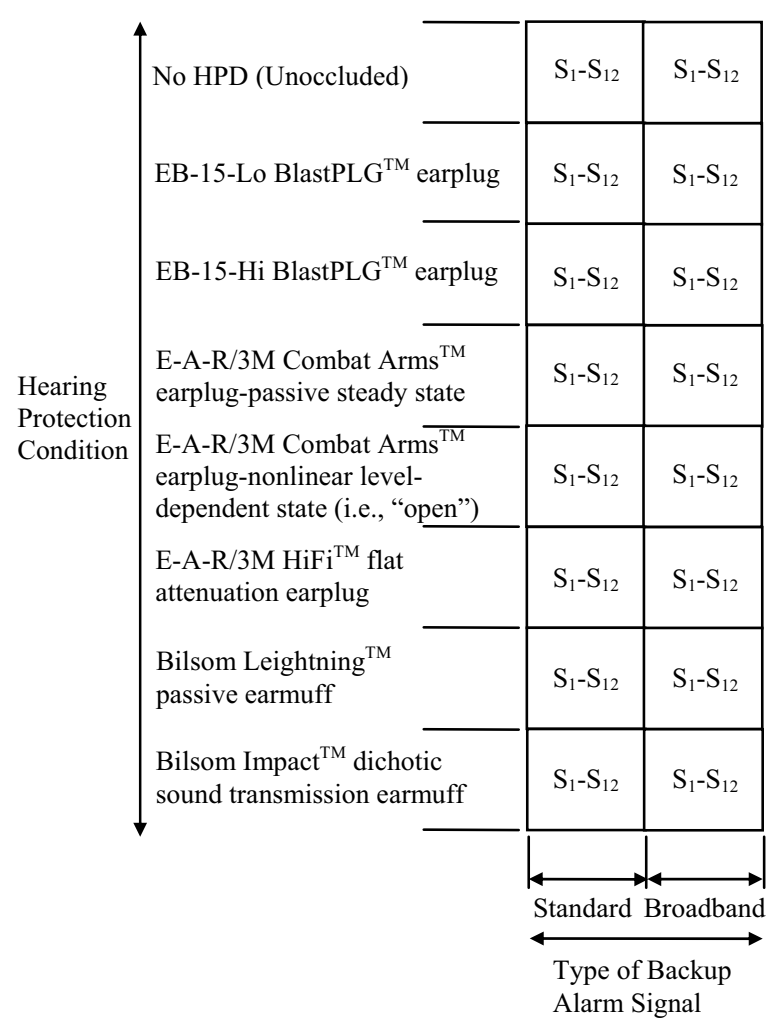

Fig.1: Experimental design block diagram with assignment of participants to independent variables.

\subsection{Independent variables}

\subsubsection{Hearing protection condition variable}

The hearing protection condition consisted of: 1) unoccluded (i.e., no HPD) condition, 2) Etymotic EB-15 active sound transmission BlastPLG ${ }^{\mathrm{TM}}$ earplug set to Lo gain position, 3) Etymotic EB-15 active sound transmission BlastPLG ${ }^{\mathrm{TM}}$ earplug set to Hi gain position, 4) E-A-R/3M Combat Arms ${ }^{\mathrm{TM}}$ earplug-passive steady state, 5) E-A-R/3M Combat Arms $^{\text {TM }}$ earplug-nonlinear, level-dependent state (sometimes called “open"), 6) $\mathrm{E}-\mathrm{A}-\mathrm{R} / 3 \mathrm{M} \mathrm{HiFi}{ }^{\mathrm{TM}}$ earplug, also marketed as the Etymotic ER-20 ${ }^{\mathrm{TM}}$ earplug (a "flat" attenuation device), 7) Bilsom Leightning $^{\mathrm{TM}}$ Hi-Visibility L3HV conventional passive earmuff, and 8) Bilsom Impact ${ }^{\mathrm{TM}}$ dichotic sound transmission electronic earmuff.

From the myriad of HPDs that are commerciallyavailable, the selection of those HPDs for this experiment was primarily based upon their incorporated special features (e.g., uniform attenuation, level-dependent attenuation, or electronic sound pass-through) that were believed to have potential for improving situation awareness for the construction worker who needs to hear auditory warnings.

The EB-15 earplug has a two-position switch (Lo and $\mathrm{Hi}$ ) and was evaluated at both of its gain settings. At the "Lo" position, the earplug attenuates loud sounds by approximately $15 \mathrm{~dB}$ and protects from impulsive sounds while allowing soft sounds to pass through. This is considered beneficial in construction environments where intermittent noise that has impulsive components is prevalent. Also, it allows the workers to communicate during quiet periods. At the "Hi" position, the earplug allows loud sounds to pass through, protects from impulsive sounds by abruptly retarding the gain, and amplifies soft sounds by about $15 \mathrm{~dB}$. Because it provides about $15 \mathrm{~dB}$ gain during quiet conditions, the EB-15 $\mathrm{Hi}$ has the potential to facilitate communications between workers.

The two-state, rocker switch-operated E-A-R/3M Combat $\mathrm{Arms}^{\mathrm{TM}}$ earplug in its third generation was selected since its level-dependent ("open") state provides low attenuation ( $\mathrm{NRR}=7$ ), while providing higher attenuation for impulsive noises; thus it is a nonlinear or level-dependent HPD in its open position. However, even in its open position it provides substantial attenuation of $18.7 \mathrm{~dB}$ at 1000 $\mathrm{Hz}$ and higher attenuation with increasing frequency. This earplug was thought to have benefit potential for certain construction environments where intermittent noise is prevalent. When the rocker switch of the Combat Arms ${ }^{\mathrm{TM}}$ is closed, the plug is in its steady state $(\mathrm{NRR}=23)$, and provides a constant protection against continuous sounds.

Unlike conventional passive earplugs which exhibit higher attenuation at high frequencies compared to attenuation at low frequencies, the E-A$\mathrm{R} / 3 \mathrm{M} \mathrm{HiFi}^{\mathrm{TM}}(\mathrm{NRR}=12)$ exhibits an approximately uniform (i.e., flat) attenuation in the $100-8000 \mathrm{~Hz}$ frequency range. As described by the manufacturer, this uniform attenuation across the aforementioned frequency range improves the listener's pitch perception. Accordingly, this intrinsic feature in the $\mathrm{E}-\mathrm{A}-\mathrm{R} / 3 \mathrm{M} \mathrm{HiFi}^{\mathrm{TM}}$ earplug was thought to have potential to improve auditory signal detection especially when the signal's acoustic energy is concentrated at higher frequencies.

The Bilsom Leightning ${ }^{\mathrm{TM}}$ Hi-Visibility L3HV passive earmuff $(\mathrm{NRR}=30)$ was selected due to its high attenuation value as a conventional earmuff. This hearing protector was believed to be applicable to the construction industry since it, as a high- 
attenuation device, is expected to fulfill the need to protect construction workers from severe background noise levels that sometimes pervade construction sites. In addition to its high attenuation, the use of this type of hearing protectors is prevalent in industry and construction.

The Bilsom Impact ${ }^{\mathrm{TM}}$ dichotic earmuff $(\mathrm{NRR}=23$ in the passive mode of operation) is an active (electronic) earmuff, also known as a sound restoration or sound pass-through device. It has microphones attached to the earcups to transmit ambient sounds (e.g., coworkers' conversations, warning signals, etc) to pass-through circuits and earphones that reside inside the earcups. As described by the manufacturer, during quiet surrounding conditions these circuits amplify ambient sounds in their passband to $82 \mathrm{dBA}$ to improve listeners' situation awareness. At the same time, the Bilsom Impact ${ }^{\mathrm{TM}}$ earmuffs are designed to protect users from high background noise levels (above $82 \mathrm{dBA}$ as described by the manufacturer) since their pass-through circuits shut-off and the earmuff reverts to a passive mode. This earmuff was included based on its potential to fulfill the aforementioned communication need for construction workers.

\subsubsection{Backup alarm signal variable}

The second independent variable investigated in this experiment was the type of the backup alarm signal. The participants' performance in judging the detection distance of the backup alarm signal was assessed under a standard narrowband backup alarm (Preco Model-6003) and a commercially-available broadband (pulsed white noise) backup alarm. The broadband backup alarm (Brigade Model BSS-97), a product of the Brigade company, is claimed by Brigade to provide better horizontal localization performance, being a "noiseless" ${ }^{\text {"[1] }}$ backup alarm signal, and travels shorter distances than tonal backup alarm signals, to reduce annoyance for nearby communities. The spectrum for each of these 97 dBA backup alarm signals is shown in Figure 2. The on-off pulse rate was 70 pulses/min for the standard and 80 pulses/min for the broadband.

\subsection{Participants}

A total of 12 participants (age range: from 18 to 32 years; gender: 7 males, 5 females) participated as subjects in the detection distance experiment. All qualifying participants were tested with a Beltone
Model 114 pure-tone audiometer and verified to have normal bilateral hearing (i.e., defined as less than or equal to $25 \mathrm{dBHL}$ at $250,500,1000,1500,2000$, 3000,4000 , and $6000 \mathrm{~Hz}$ in both ears).

\subsection{Apparatus}

\subsubsection{Experimental sound field}

A long, open field with no substantial barrier obstructions or reflective boundary buildings in the city of Radford, Virginia, USA was used as a testing environment. This provided a $2000 \mathrm{ft}$ long by $50 \mathrm{ft}$ wide unobstructed, grassy field in which all tests were performed. The two backup alarms used in this study, the Brigade broadband backup alarm signal and the Preco narrowband backup alarm signal were both operated at their standard output level of 97 dBA per SAE standard J994-2009. To operate these two backup alarms in the open field, a portable 12Volt battery was used, and it was fully charged prior to each session. To determine the distance between the point where the signal was detected by the participant and the source of the backup alarm, a Tooluxe LCD measuring wheel was used.

\subsubsection{Ambient noise measurements}

A Larson-Davis sound level meter and real time analyzer system, model 824 , was used to obtain the sound pressure level at the detection distance, as well as the field's ambient A-weighted equivalentcontinuous noise level with an averaging time of 15 minutes $\left(\mathrm{L}_{\text {Aeq, }} 15 \mathrm{~min}\right)$. At the middle of the field, the typical ambient level was $52.3 \mathrm{dBA}$ (slow), thus the field was relatively quiet compared to the backup alarms. In addition, the same system was used to obtain the backup alarms' spectra in the testing field. Interfaced with this meter was a Larson-Davis model 2559 1/2-inch microphone, and the system was calibrated to $94 \mathrm{dBA}$ at $1 \mathrm{kHz}$ using a Quest QC-20 calibrator. 


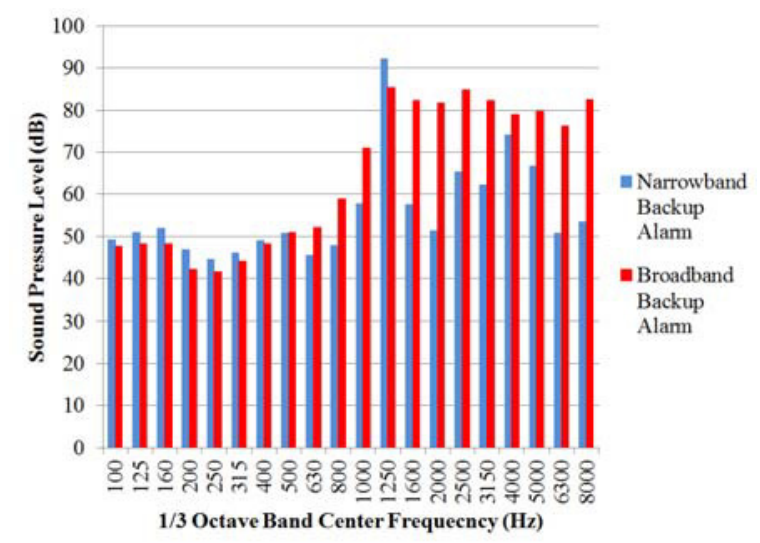

Fig.2: Standard (Preco Model-6003) and broadband (Brigade Model BSS-97) backup alarm spectra as measured in an open field over a grassy surface at four feet away from the alarm source with the measurement microphone at four feet off the ground.

\subsection{Procedure}

Participants first underwent a screening session after they read and signed an informed consent document. In this session, the condition of the ear canal and tympanum of the participant was checked using an otoscope, and if normal, his/her hearing levels were determined using the audiometer. Next, in the experimental session, the participant was instructed in the procedure of the experiment. The method of limits, with distance as the physical measurement variable, and threshold detection as the task, was employed to find at which distance the participant could first detect the backup alarms. Under each hearing protection or open ear condition, the participant walked slowly away from the backup alarm signal until the signal was no longer audible (Ascending Trial). The distance from the backup alarm was then recorded. Next, he/she was instructed to move even further away (by about $10 \mathrm{ft}$ ), turn around, and begin moving slowly toward the backup alarm signal until the signal was just barely audible (Descending Trial). The distance from the backup alarm was then again recorded. The ascending and descending trials were repeated a total of two times for each HPD condition under each type of backup alarm. Presentation of the two backup alarms was carried out in a random fashion to avoid order effects. Also, the order effect of assigning hearing protection and open ear conditions to each participant was counterbalanced by a repeated-non-identical complete Latin Square.

\subsection{Dependent measures}

One dependent measure was acquired in this study, the detection distance in feet. It was defined as the distance between the actual backup alarm device and the position where the participant detected the backup alarm signal. For each HPD condition under each type of backup alarm, this position was determined by computing the arithmetic mean of the distances at detection point on the ascending and descending portions of the two trials.

\section{Results}

\subsection{Data reduction and statistical analysis}

The two pairs of captured ascending and descending trial data for each condition were entered into a Microsoft Excel ${ }^{\mathrm{TM}}$ program and averaged for each subject under each HPD and backup alarm condition. These averaged data were used as data points in the statistical analysis. To show any statistically-significant differences, at an alpha level of 0.05 , between the levels of the independent variables, a within-subject Analysis of Variance (ANOVA) was applied. Any significant difference revealed by ANOVA was further analyzed by a Tukey's Honestly Significant Difference (HSD) test, also at an alpha level of 0.05. The Statistical Analysis Software (SAS) program was used to conduct the ANOVAs and the Statistical Minitab software, in addition to the Microsoft Excel ${ }^{\mathrm{TM}}$ program, were used to generate the mean and confidence intervals graphs included herein, with mean values shown on the data bars and $95 \%$ confidence limits plotted.

\subsection{Hearing protection device (HPD) main effects}

For the detection distance in feet, the ANOVA revealed a significant main effect of HPD. The HPD effect on detection distance was highly significant, $F(7,77)=45.8, p<0.0001$ (Table 1 ), with the means ranging from a low (i.e., worst) of $1132.2 \mathrm{ft}$ for the Bilsom passive earmuff to a high (i.e., best) of $1652.3 \mathrm{ft}$ for the unoccluded condition (Figure 3). Post hoc analyses via Tukey's test indicated that the Bilsom passive earmuff (at $1132.2 \mathrm{ft}$ ) was significantly poorer than all other HPDs and the open ear listening condition in detection distance achieved, and that there were no statistically-significant differences between the unoccluded ear $(1652.3 \mathrm{ft})$, 
EB-15-Lo $\quad$ BlastPLG $^{\mathrm{TM}} \quad(1546.2 \quad \mathrm{ft}), \quad$ EB-15-Hi BlastPLG $^{\mathrm{TM}}$ (1543.4 ft), E-A-R/3M Combat Arms ${ }^{\mathrm{TM}}$ earplug-nonlinear, level-dependent state $(1507.8 \mathrm{ft})$, E-A-R/3M HiFi ${ }^{\mathrm{TM}}$ earplug $(1497.7 \mathrm{ft})$, and Bilsom Impact $^{\mathrm{TM}}$ dichotic earmuff $(1567.2 \mathrm{ft})$. In addition, the detection distance in feet while using the E-A$\mathrm{R} / 3 \mathrm{M}$ Combat Arms ${ }^{\mathrm{TM}}$ earplug-passive steady state differed significantly from only the open ear condition, at $1474.1 \mathrm{ft}$ versus $1652.3 \mathrm{ft}$ for the open ear.

\subsection{Backup alarm signal (BU) main effects}

The backup alarm signals' significant main effect on the detection distance in feet was revealed via ANOVA. The means were $1600.9 \mathrm{ft}$ for the standard backup alarm signal and $1379.4 \mathrm{ft}$ for the broadband backup alarm signal (Figure 4), with ANOVA statistics of $F(1,11)=18.8, p=0.0012$ (Table 1). Clearly, the broadband backup alarm was at a 221.5 $\mathrm{ft}$ disadvantage in detection distance.

Table 1 .

ANOVA Summary table for the detection distance in feet (bold text indicates significance at $p \leq 0.05$ ).

\begin{tabular}{lcccc}
\hline Source & df & MS & $F^{* *}$ & $P r>F$ \\
\hline HPD & $\mathbf{7}$ & $\mathbf{5 7 2 4 5 0 . 3}$ & $\mathbf{4 5 . 8}$ & $<\mathbf{0 . 0 0 0 1}$ \\
\hline HPD $\times$ S & 77 & 12506.2 & ----- & ------- \\
\hline BU & $\mathbf{1}$ & $\mathbf{2 3 5 4 6 5 5 . 8}$ & $\mathbf{1 8 . 8}$ & $\mathbf{0 . 0 0 1 2}$ \\
\hline BU $\times$ S & 11 & 124952.1 & ----- & ------ \\
\hline HPD $\times$ BU & 7 & 5008.9 & 0.5 & 0.8207 \\
\hline HPD $\times$ BU $\times S$ & 77 & 9728.7 & ----- & ------
\end{tabular}

${ }^{*} \mathrm{HPD}=$ Hearing Protection Device, $\mathrm{BU}=$ Backup Alarm, $\mathrm{S}=$ Subjects.

${ }^{* *}$ Each $F$-ratio consists of the source of variance under test in the same row, divided by the error term for that source in the immediately following row.

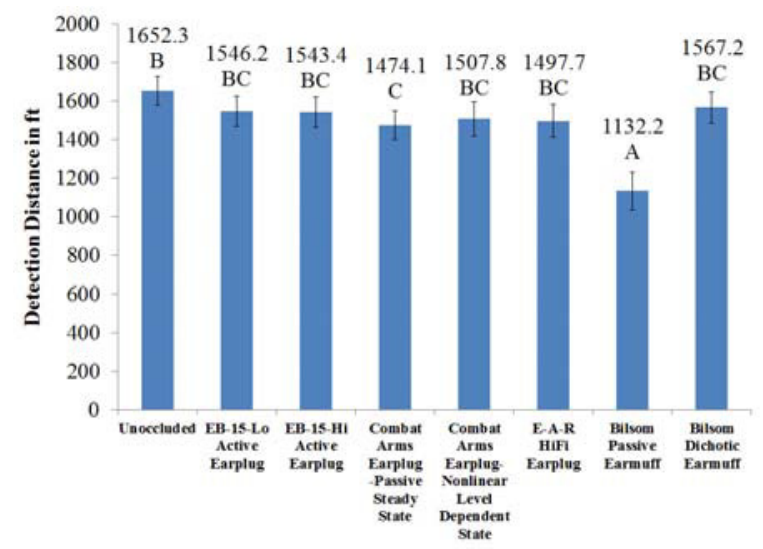

Fig.3: Main effect of HPDs on detection distance in feet, with mean values shown on bars with $95 \%$ confidence intervals plotted. Means with the same letter are not significantly different $(p \leq$ 0.05 ) according to Tukey's test.

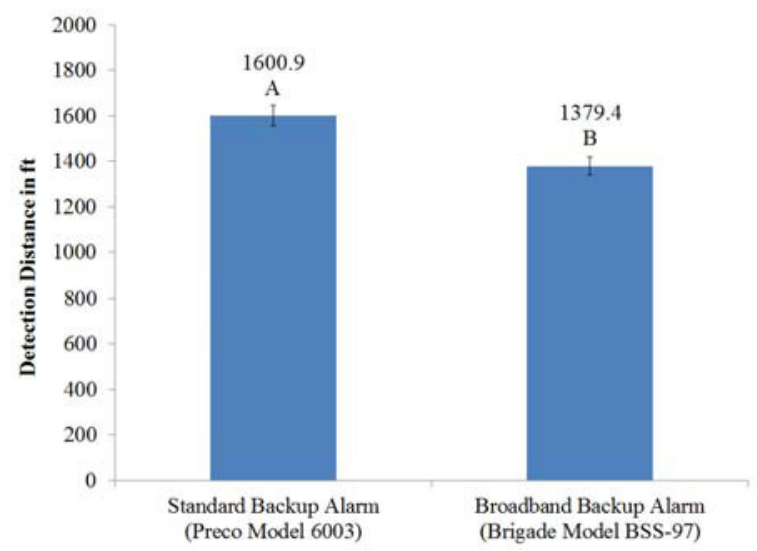

Fig.4: Main effect of backup alarm type on detection distance in feet, with mean values shown on bars with $95 \%$ confidence intervals plotted. Means with the same letter are not significantly different $(p \leq 0.05)$.

\section{Discussion and conclusion}

\subsection{Conclusions regarding HPDs and detection distance}

For on-ground workers, it is crucial to detect backup alarm signals as far away as possible rather than at close distances since this will provide them more time to react to approaching vehicles. The main objective for this experiment was to investigate how the distance where the backup alarm signal can be detected (i.e., operationally termed 'distance-atdetection' or 'detection distance') in a free field is affected by the various HPDs versus the open ear. The significant differences found between certain HPDs have demonstrated that the choice of a hearing protector can influence this detection distance. As shown in Figure 3, the E-A-R/3M Combat Arms ${ }^{\mathrm{TM}}$ earplug-passive steady state and the Bilsom passive earmuff were the only devices to significantly degrade the detection distance when compared to that of the unoccluded ear condition. On the other hand, there was no difference between the other tested HPDs, or between any of them and the unoccluded ear condition. These results suggest that the selection of devices having attenuation comparable to the E-A$\mathrm{R} / 3 \mathrm{M}$ Combat Arms ${ }^{\mathrm{TM}}$ earplug-passive steady state and the Bilsom passive earmuff by construction site 
safety professionals should be made with precaution. However, this selection decision must be balanced with consideration for the necessary protection needed for severe noise exposures encountered in some construction environments.

\subsection{Conclusions regarding backup alarm signal type and detection distance}

The main effects of the type of backup alarm signal demonstrated a statistically-significant detection advantage of the standard backup alarm over the broadband backup alarm as measured in detection distance in feet. The magnitude of the improvement produced by the standard backup alarm over the Brigade ${ }^{\mathrm{TM}}$ alarm was 221.5 feet, a large margin. Such a large deficit in detection distance under the Brigade broadband alarm gives rise to the need for caution in its selection for work environments that include construction vehicles, and particularly for those with high reversing speeds. For instance, for a vehicle backing at $10 \mathrm{mph}$ (a rubbertire loader, for example), the $221.5 \mathrm{ft}$ decrease in detection distance equates to the vehicle arriving 15 seconds sooner at the worker's position from the point at which its alarm was first heard. It should be obvious that on-ground construction workers have more distance, and thus more time, to react to approaching vehicles when a standard backup alarm is installed on construction site vehicles than would workers at a site where a broadband backup alarm is being used. However, this being said, due to its inclusion of more frequency bandwidth, there could be an offsetting advantage of the broadband alarm in vehicle localization, though this remains to be proven experimentally.

\subsection{Post-hoc correlation analysis: backup alarm versus attenuation spectra}

As shown in Figure 3, the Bilsom passive earmuff provided the minimum (i.e., worst) detection distance. This was believed to be largely due to its high attenuation characteristics compared to most other HPDs used in the detection distance experiment. Thus, to further explore the relationship between an HPD's attenuation and detection distance, backup alarm levels at listeners' earcanals (i.e., the difference between the backup alarm level and the amount of attenuation, see Figures 5 and 6) at the following frequencies: 500, 1000, 2000, 3150, 4000, and $6300 \mathrm{~Hz}$ were correlated against the detection distance for the four tested passive HPDs (E-A-R/3M Combat Arms ${ }^{\mathrm{TM}}$ earplug-passive steady state, E-A-R/3M Combat Arms ${ }^{\mathrm{TM}}$ earplug-nonlinear, level-dependent state, E-A-R/3M HiFi ${ }^{\mathrm{TM}}$ earplug, and Bilsom Leightning ${ }^{\mathrm{TM}}$ Hi-Visibility L3HV passive earmuff). The Etymotic EB-15 active sound transmission BlastPLG ${ }^{\mathrm{TM}}$ earplug and the Bilsom Impact $^{\mathrm{TM}}$ dichotic sound transmission earmuff were not considered in this correlation analysis since they were set at gain positions where they provided essentially no attenuation at the low sound levels present in the experiment.

Using the parametric Pearson correlation test, the correlation between the standard backup alarm's levels at the listeners' ear position and the detection distance was strong, positive, and significant $(r=0.6$ and $p=0.003)$. Likewise, the Pearson correlation revealed a strong, positive, and significant correlation ( $r=0.5$ and $p=0.015$ ) between the broadband backup alarm's levels at the listeners' ear and the detection distance. Since human hearing is most sensitive in the 1000 to $4000 \mathrm{~Hz}$ frequency region, and since the standard backup alarm has dominant energy in the range of 1250 to $4000 \mathrm{~Hz}$, another correlation test was applied on only 1000, 2000, 3150, and $4000 \mathrm{~Hz}$. The Pearson test revealed a strong, positive, and significant correlation between the standard backup alarm's levels at the listeners' position and the detection distance $(r=0.5$ and $p=$ 0.038 ), and a similar result for the broadband backup alarm $(r=0.6$ and $p=0.008)$. These results partially supported the conclusion that as the amount of HPD attenuation increases, the detection distance decreases as well. As depicted in Figures 5 and 6, passive HPDs which had high attenuation (i.e., the EA-R/3M Combat Arms ${ }^{\mathrm{TM}}$ earplug-passive steady state, and the Bilsom Leightning ${ }^{\mathrm{TM}}$ Hi-Visibility L3HV passive earmuff) provided shorter (i.e., worse) detection distances than did those HPDs with low attenuation (i.e., E-A-R/3M Combat Arms ${ }^{\mathrm{TM}}$ earplug-nonlinear, level-dependent state, E-A-R/3M $\mathrm{HiFi}^{\mathrm{TM}}$ earplug). 


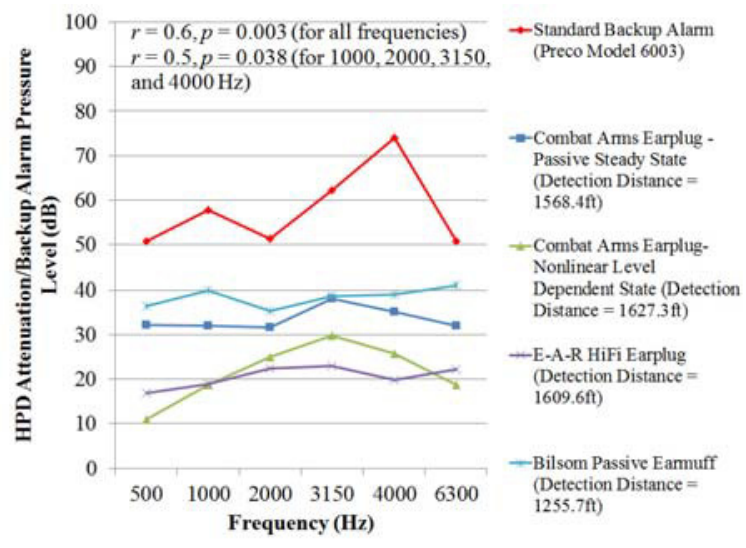

Fig.5: Attenuation profile for the passive HPDs tested in the detection distance experiment versus the spectrum of the standard backup alarm. The detection distance mean in feet is shown for each passive HPD for the standard backup alarm. (See text.)

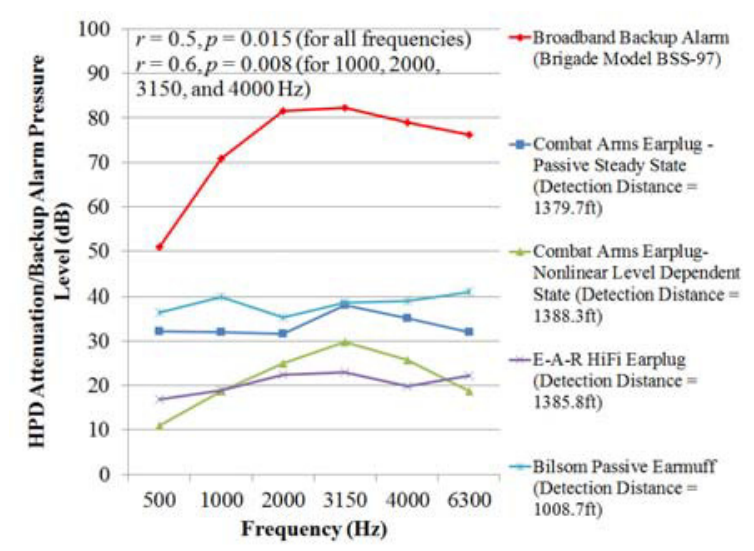

Fig.6: Attenuation profile for the passive HPDs tested in the detection distance experiment versus the spectrum of the broadband backup alarm. The detection distance mean in feet is shown for each passive HPD for the broadband backup alarm. (See text.)

\section{Recommendations for application of the results and future research}

The research was comprised of a two variable, complete factorial experiment with one dependent measure of detection distance performance. Based on the statistical analyses of the resultant data, it is clear that there are differences in normal-hearing listeners' detection distance performance that depends upon both HPD type/design and backup alarm spectral content. It must also be kept in mind that the dBA level of the alarms was not a factor since it was a constant $97 \mathrm{dBA}$ for both alarms in accordance with the SAE J994-2009 standard.
The results of this study partially suggest that as the attenuation of the hearing protectors increases, certain precautions should be considered by the construction sites' safety professionals. This is because, as it was the case with the Bilsom passive earmuff and E-A-R/3M Combat Arms ${ }^{\mathrm{TM}}$ earplugpassive steady state, high attenuation significantly reduces the detection distance, and as a result, onfoot workers will have less time to react to any approaching vehicle. Again, the selection decision should not be based solely on these situation awareness considerations, since protective effectiveness for high level exposures is also of high importance.

Also, the results showed an advantage of the standard (narrowband) backup alarm signal over the broadband backup alarm signal in terms of detection distance. The broadband Brigade ${ }^{\mathrm{TM}}$ backup alarm manufacturer claims that its alarm is advantageous in providing better horizontal localization performance, being a "noiseless" backup alarm signal, and traveling shorter distances than tonal backup alarm signals to reduce annoyance. This may indeed be true, and in certain situations, the priority may be to provide "noiseless" and localizable warning alarms; however, in most construction sites, the priority must be to provide an increased envelope of safety for onfoot workers via an alarm which is detectable over long enough distances to afford adequate evasion time. The results of this study showed that the standard (narrowband) backup alarm signal provides more distance, and therefore more time, for on-foot workers to react to backing vehicles compared to the broadband backup alarm signal. It must be recognized that this conclusion is based on an experiment with specific conditions, and thus the results may not be generalizable to other backup alarm signals, or to other HPDs.

More research is needed concerning the effects of other variables that exist in construction sites (e.g., masking noises that exist in road construction sites) on detection distance. In terms of hearing acuity, workers in industry and construction can be categorized as workers with normal hearing and those with impaired hearing. Since all the participants who participated in this study had normal hearing, more research is needed to determine how listeners with impaired hearing will perform in detection distance tasks.

Finally, more attention needs to be devoted to the development and testing of hearing protectors that provide better auditory situational awareness for construction workers, and a systems-design approach 
needs to be adopted to integrate these protective devices to the alarm signals which are critical to workers' safety.

\section{References}

[1] Brigade Electronics. (2008). Broadband sound: The safer and noiseless back-up alarm [White paper]. Retrieved from http://www.brigade-inc.com/uploads/bbs-tek-white-paper.pdf

[2] Casali, J. G., \& Lancaster, J. A. (2008). Quantification of and solutions to the impediments to speech communication and signal detection in the construction industry: Final report (No. VTSP 4/15/08-3-HP). Blacksburg, VA: Virginia Polytechnic Institute and State University, Auditory Systems Laboratory.

[3] Occupational Safety \& Health Administration (2000). Safety and health regulations for construction: Material handling equipment (29 CFR, Part 1926.602). Washington, DC: Office of Federal Register.
[4] Occupational Safety \& Health Administration (2000). Safety and health regulations for construction: Motor vehicles (29 CFR, Part 1926.601). Washington, DC: Office of Federal Register.

[5] Pratt, S. G., Fosbroke, D. E., \& Marsh, S. M. (2001). Building safer highway work zones: Measures to prevent worker injuries from vehicles and equipment (No. 2001-128). Cincinnati, OH: National Institute for Occupational Safety and Health.

[6] Purswell, J. P., \& Purswell, J. L. (2001). The effectiveness of audible backup alarms as indicated by OSHA accident investigation records. In A. C. Bittner, P. C. Champney, \& Morrissey (Eds.), Advances in Occupational Ergonomics and Safety (pp. 444-450). Amsterdam, Netherlands: IOS Press. 